\title{
Scores and Principal Components: The Relationship between Components due to Subjects and to Variables
}

\author{
Horacio J.A. Rimoldi Elsa Bei de Libonatti \\ CIIPME: CONICET \\ University of Buenos Aires \\ University El Salvador
}

The main purpose of this article is: given a score matrix called $S$, find out the joint proportional contribution of factors due to persons (conditions, situations, and so forth) and factors due to variables, for any $s_{i j}$ observed score, where $i$ identifies persons, and $j$, variables. This approach makes it possible a) to show that the same score in a given variable may have a different quantitative interpretation in terms of persons or conditions, and b) to find out how subjects differ in the way in which they relate variables.

Key words: principal components, factor contribution

\begin{abstract}
El propósito de este artículo es determinar la contribución proporcional de factores debidos a las personas (condiciones, situaciones, etc.) y factores debidos a las variables, dada una matriz $S$ donde se presentan las calificaciones obtenidas por $m$ sujetos en $n$ variables. Siguiendo el procedimiento descrito es posible: a) demostrar que la misma puntuación en una variable puede tener diferente interpretación cuantitativa según las personas, y b) averiguar cómo difieren los sujetos en su forma de relacionar las variables implicadas.

Palabras claves: componentes principales, contribución de factores
\end{abstract}

The authors thank Dr. R.B. Cattell for his comments on an earlier version of this article, and Dr. L.A. Santaló and Dr. G.K. Burger for their comments on the present manuscript, as well as Mr. A. Salinas and Mr. F. Lagoutte for their help in planning and performing the pertinent computations.

Cortespondence concerning this article should be addressed to Dr. Rimoldi, Tte. Gral. Perón 2158. 1040 Buenos Aires (Argentina). Fax: 5411 4953-3541.E-mail: ciipme@ssdnet.com.ar 
Much of the psychometric literature is concerned with the development of instruments that make it possible to characterize and compare samples of subjects. These evaluations do not often consider the joint contribution of factors due to persons, and factors due to variables, to a given score. However, it is possible to show: a) that the same score in the same variable may be a function of different components due to subjects, so that individual differences may be psychometrically appraised in spite of equal scores, and b) that different subjects may relate variables in diflerent ways beyond the correlations that exist between the variables.

As stated by Thurstone (1969), the performance of a person in a test is determined in part by the abilities that are called forth by the test, and in part by the degree to which the subject possesses these abilitics. With reference to the factor analysis of persons, Burt $(1937,1941)$ suggested that the reciprocity principle holds if the initial matrix is suitably standardized so that the resulting factors will be the same whether they come from covariating persons or covariating tests. In two chapters of "The factorial analysis of human ability", Thomson (1951, p.219) stated that Burt's formulation of the problem is fulfilled under "very special circumstances," given that "we can write down an infinity of possible raw matrices from which Burt's doubly centered matrices might have come."

Sandler $(1949,1952)$ described how to obtain the person's factors, starting from a matrix centered only one way. According to him, appropriate units are required to show Burt's (1941) reciprocity principle. He recommended factorizing the product sum between persons, using a matrix presented in normalized form.

Early in the thirties, Stephenson $(1935,1936)$ presented a possible solution to the problem concerning the factor analysis of persons instead of tests. A thorough description of his $\mathrm{Q}$ technique was offered in relation to the $\mathrm{R}$ and $\mathrm{P}$ techniques, stating that: "in $\mathrm{R}$, the tests are meant to measure 'abilitics' by way of individual differences; in Q, they would be used to experiment upon certain attitudes of mind of "any' person we care to make the subject of inquiry" (Stephenson, 1953, p.16). According to him, Cattell's P technique "is merely our system." Cattell's contribution to the problem has been developed and applied in different contexts (Cattell, 1950,1952,1963, 1965, 1978, 1979, 1980).

In terms of what Burt (1941) originally called the reciprocity principle, Holley and Guilford (1964) described an index of agreement or co-relation called $\mathrm{G}$, which Holley (1964) used to make the transition between $R$ and $Q$ factors. According to Holley, $\mathrm{G}$ indexes are equal to the values of $S S / N$ and $S S / N$ matrices, if the scores are dichotomized with values of +1 and -1 . Under such circumstances, $G$ indexes solve the transition without double centering the matrix. In another article, Holley (1970) stated that the linking of the $Q$ and $R$ factors may be successfully accomplished using the $G$ index in matrices containing dichotomous entries. The same author, together with Harris
(Holley \& Harris, 1970), offered another solution to the transition between the $\mathrm{Q}$ and $\mathrm{R}$ matrices based on the correlations between persons obtained when the score matrix contains only values of zero and one. In 1978, Hasktian and Cattell performed a study in which the three-mode factor analysis, described by Tucker (1967) and Levin (1964), was applied to study the interdomain relationships between ability and personality traits. The relationship between factors due to persons and to variables was examined in a study by Burger and Rimoldi (1997).

In the previously mentioned studies, some kind of transformation was applied to the original $s_{i j}$ scores. Some of these transformations may change the relationship that exists between the actual $s_{i j}$ scores when examined in terms of both subjects and variables.

In the present study, given a nonsingular score matrix called $S$, and using either principal components or varimax solutions, we shall try to find out: a) how the results obtained by factorizing the inner product of the column vectors-that usually represent variables-may be used to discover the factors resulting from the inner product of the row vectors-that usually represent subjects-and how the results obtained by factorizing the inner product of the row vectors may be used to find out the factors corresponding to the inner product of the column vectors; b) how to obtain the factor loadings corresponding to subjects and to variables by multiplying $S$ by any orthogonal matrix; c) what changes in factor loadings may be expected when projecting the score matrix $S$ on a hyperspace corresponding to specified hypotheses or conditions; and d) how the same score may result from a different proportional contribution of factors due to persons and factors due to variables.

a) Given an $(m \times n)$ matrix $S$ of raw scores $s_{i j}$ for $i=$ $1,2, \ldots, i, \ldots m$ and $j=a, b, \ldots, j \ldots n$, find the relationship that exists between factors obtained from the $(m \times m)$ matrix $(S S)$ with those obtained from the $(n \times n)$ matrix $S ' S$. Whereas (SS) contains the inner product of the row vectors of $S$, the inner product of the column vectors is given by $(S ' S)$.

Using $F_{r}$ and $V_{r}$, respectively, as the principal axis and varimax solutions for $S^{\prime}$, we obtained:

$S S^{\prime}=F_{r} F_{r}^{\prime}=V_{r} V_{r}^{\prime}$,

where $F_{r}$ and $V_{r}$ represent the principal axis and varimax solution for the inner product of the row vectors of $S$ and

$S S=F_{r} F_{c}^{\prime}=V_{r} V_{c}^{\prime}$,

where $F_{c}$ and $V_{c}$ represent, respectively, the principal axis and varimax solution for the inner product of the column vectors of $S$.

Under the specified condition,

$F_{r}^{\prime} F_{r}=F_{c}^{\prime} F_{c}=D=E_{d} E_{d}$, 
where $D$ is a diagonal matrix of eigenvalues and $E_{d}$ its principal axes solution. However, when using varimax solutions, $V_{r}^{\prime} V_{r} \neq V_{r}^{\prime} V_{c}$ so that

$V_{r}^{\prime} V_{r}=D_{r}=E_{r} E_{r}^{\prime}$

and $V_{c}^{\prime} V_{c}=D_{c}=E_{r} E_{c}^{\prime}$,

where $E_{r} \neq E_{r}$.

There is an $(n \times n)$ orthogonal matrix $W_{r}$ by both rows and columns (Rimoldi, 1990), such that:

$W_{r}=S\left(F_{r}^{-1}\right)$

and an $(m \times n)$ orthogonal matrix $W_{c}$ by columns, such that:

$W_{c}=S\left(F_{c}^{-1}\right)$.

Then, it can be shown that:

$S=F_{r} W_{r}^{\prime}=W_{c} F_{c}^{\prime}$

from which, according to (8), (3), and (1) we obtain:

$S S^{\prime}=W_{c} F_{c}^{\prime} F_{c} W_{c}^{\prime}=W_{c} D W_{c}^{\prime}=\left(W_{c} E_{d}\right)\left(E_{d} W_{c}^{\prime}\right)=F_{r} F_{r}^{\prime}$

and $S S=W_{r} F_{r}^{\prime} F_{r} W_{r}=W_{r} D W_{r}^{\prime}=\left(W_{r} E_{d}\right)\left(E_{d} W_{r}^{\prime}\right)=F_{c} F_{c}^{\prime}$

From (6), (7), (9), and (10), it follows that:

$F_{r}=W_{c} E_{d}=S\left(F_{c}^{-1}\right)^{\prime} E_{d}$

and, $F_{c}=W_{r} E_{d}=S^{\prime}\left(F_{r}^{-1}\right) E_{r}$,

so that, knowing $F_{r}$ and $S, F_{r}$ can be obtained (equation $11)$, and from (12), it follows that, knowing $F_{r}$ and $S, F_{c}$. can be obtained.

When using a varimax solution (6) and (7) become:

$X_{r}=S\left(V_{r}^{-1}\right)^{\prime}$

and, $X_{r}=S\left(V_{c}^{-1}\right)$,

so that, $S=V, X_{r}^{\prime}=X_{c} V_{c}^{\prime}$,

From these results, it follows that equations (11) and (12) can be modified to incorporate varimax solutions, so that:

$F_{r}=S\left(F_{c}^{-1}\right) E_{d}=S\left(V_{c}^{-1}\right) E_{c}$

and $F_{c}=S^{\prime}\left(F_{r}^{-1}\right) E_{d}=S^{(}\left(V_{r}^{-1}\right) E_{r}$.

The previous development satisfies Horst's (1963) concept of basic structure of a matrix. b) Obtaining $F_{r}$ and $F_{c}$ by multiplying $S$ by any orthogonal matrix called $O$, and replacing the orthogonal matrix called $W_{r}$ in equation (6) with the $(n \times n)$ orthogonal matrix $O$, we can write:

$O=S\left(z^{-1}\right)$

for $Z=S O$. $E_{z}$.

The principal axes solution for $Z Z=D_{z}$ will be named

By analogy with equation (17), replacing $E_{d}$ with $E_{z}$ and $S\left(F_{r}^{-1}\right)$ with $O$ we find that:

$F_{i}=O E_{z}$.

Summarizing: the matrix $S$ may be multiplied by any orthogonal matrix to obtain matrix $Z$, and the product $Z^{\prime} Z$ when factorized, provides matrix $E_{3}$, which, when premultiplied by $O$, provides matrix $F_{r}$.

c) Changes in factor loadings when projecting $F_{r}$ on another hyperspace.

Let $A$ be an $(m \times n)$ score matrix obtained under different conditions than $S$, or developed under a specific hypothesis. The purpose is to find out how the factor solution previously identified by $F_{r}$ will change when projected on the $A$ hyperspace.

Define $M_{a}=\left[A\left(F_{a}^{-1}\right)\right]$, where $F_{a}$ results from an orthogonal factorization of $A A^{\prime} . \quad M_{a}$ will be an orthogonal matrix equivalent to $W_{r}$, as seen in (5), and the projection of $S$ on the $A$ hyperspace will be:

$F_{r a}=S\left[A^{\prime}\left(F_{a}^{-1}\right)^{\prime}\right]=S M_{a}$.

d) The proportional contribution of factors due to persons to a given $s_{i j}$ score.

Let $w_{j k}$ represent the factor loading for variable $j$ in factor $k$, where $k=1,2, \ldots \ldots, k, \ldots \ldots . N$ corresponds to the orthogonal factorization of $\left(S^{\prime} S\right)$, and let $w_{i k}{ }^{\prime}$ correspond to the factor loading of person $i$ in factor $k^{\prime}$, where $k^{\prime}=1^{\prime}$, $2^{\prime}, \ldots \ldots . k^{\prime}, \ldots \ldots . . . N^{\prime}$ corresponds to the orthogonal factorization of $S S^{\prime}$ Then:

$\sum_{i=1}^{m} s_{i j}^{2}=\sum_{k=1}^{N} w_{j k}^{2}=Q_{j}$

where $Q_{j}$ corresponds to the squared length of the column vectors in $S$ or to the row vectors in $F_{c,} V_{c}$ or any orthogonal factorization of $S$ S. Similarly:

$\sum_{j=i}^{n} s_{i j}^{2}=\sum_{k^{\prime}=1}^{N} w_{i k}^{2}=Q_{i}$

The proportional contribution of $w_{j k}$ to $Q_{j}$, is given by:

$p_{j k}=\frac{w_{j k}^{\frac{2}{k}}}{Q_{j}}$ 
and $\sum_{k=!}^{N} p_{j k}=1.00$

and $p_{i k^{\prime}}=\frac{w_{i k^{2}}^{2}}{Q_{i}}$

and $\sum_{k^{\prime}=\mathrm{I}^{\prime}}^{N^{\prime}} p_{i k^{\prime}}=1.00$

where $p_{i k}$. corresponds to the proportional contribution of $w_{i k}$ to $Q_{i}$.

From (24) and (26) we obtain that, for subject $i$ and variable $j$, we can state:

$\left(p_{j 1}+p_{j 2}+\ldots+p_{j k}+\ldots+p_{j N}\right)$

$\left(p_{i 1}+p_{j 2^{\prime}}+\ldots+p_{j k^{\prime}}+\ldots+p_{j N^{*}}\right)=1.00$,

so that, for instance, the joint contribution of Factors 2, due to variable $j$, and $1^{\prime}$, due to person $i$, to $s_{i j}$ is given by $\left(p_{j 2} p_{i 1}\right)$, and, similarly, for any other possible combination of factors resulting from factorizing $S S^{\prime}$, with the factors resulting from factorizing $S S$. The general designation for the products in equation (27) will be $p_{k k}$, where the first subindex corresponds to the variable factor and the second subindex to the person factor. For instance, $p_{j 2}$ and $p_{i 1}$. correspond to the joint proportional contribution of the loadings in Factor 2 of the variables and the loadings in Factor $1^{\prime}$ of the persons, and similarly for any other combination of $p_{j k}$ with $p_{i k}$, values.

\section{Applications of the Described Procedures}

The previous formulations were tested in a variety of problems that included both real data and specially prepared matrices where specific markers were introduced to test the method. The results showed that the correspondence between the principal component solution and the characteristics of the current data, as provided by the original matrix $S$, was maximal when the current, nontransformed, scores were used. As previously stated, we factorized the $S S^{\prime}$ product, which corresponds to the inner product of the row vectors of $S$, and the $S ' S$ product, which corresponds to the inner product of the column vectors of $S$. The diagonal of these product matrices contains the square length of the row and column vectors, respectively. Thus, the sum of the squared factor loadings for subject $i$ will be equal to the sum of the squared $s_{i j}$ values for the same person across all the variables, as shown in equation (22). Similarly, equation (21) indicates that the sum of the squared $s_{i j}$ values across all subjects will be equal to the sum of the squares of the factor loadings for the corresponding variable.

According to Cronbach (1992), the factor analysis procedure to be used will depend on the problem under study. In our case, the previous considerations and the results obtained with marker variables recommended the use of nontransformed $s_{i j}$ scores.

Using the approach described above, factor loadings may have extremely different values. We overcame this difficulty by using equations (23) and (25), which show the proportional contribution of each factor to variables and persons, respectively.

Our findings resulted from the analysis of data published by Hojat, Erdmann, Robeson, Damjanov, and Glaser (1992), which included scores in the following six variables: a) cognitive variables represented by Science Problems Test (S) and the Reading Test (R), both from the Medical College Admission Test (MCAT); b) the noncognitive variables included the scores in the Anxiety Test (AN), Patient Management (PM), Self-Esteem (SE), and Data Gathering (D). In the present article, we used the scores obtained in the following variables: $\mathrm{R}, \mathrm{D}, \mathrm{AN}, \mathrm{PM}$, and SE.

Table !

$p_{k k}$ Values for Four Subjects in Two Variables

\begin{tabular}{|c|c|c|c|c|c|c|}
\hline \multirow[b]{4}{*}{ Subjects } & & & \multicolumn{4}{|c|}{ Variables } \\
\hline & & & \multicolumn{2}{|c|}{$\mathrm{D}$} & \multicolumn{2}{|c|}{ AN } \\
\hline & & & \multicolumn{4}{|c|}{ Factors $\& p_{i k}$ Values } \\
\hline & \multicolumn{2}{|c|}{ Factors $\& p_{i k}$, values } & 1 & 2 & 1 & 2 \\
\hline \multirow[t]{2}{*}{13} & & .672 & .221 & .440 & .425 & .241 \\
\hline & & .303 & .100 & .198 & .191 & .109 \\
\hline \multirow[t]{2}{*}{39} & $1^{\prime}$ & .349 & .115 & .229 & .220 & .125 \\
\hline & $2^{-}$ & .640 & .211 & .420 & .404 & .230 \\
\hline \multirow[t]{2}{*}{14} & $1^{\prime}$ & .484 & .159 & .317 & .306 & .174 \\
\hline & $2^{\prime}$ & .487 & .160 & .319 & .308 & .175 \\
\hline \multirow[t]{2}{*}{74} & $1^{\prime}$ & .466 & .154 & .306 & .295 & .167 \\
\hline & $2^{\prime}$ & .527 & .174 & .346 & .333 & .189 \\
\hline
\end{tabular}

Note. $\mathrm{D}=$ Data gathering: $\mathrm{AN}=$ Anxiety Test. 
When calculating the $p_{k \downarrow}$. values, only those higher than .01 were considered. In view of this limitation, and considering that, in both the varimax solutions for subjects and for variables, two factors accounted for over $98 \%$ of the variance, we decided to operate with only two $p_{i k}$ and two $p_{j k}$ values to calculate the corresponding $p_{k k}$. With other data, the number of $p_{i k}$ and $p_{j k}$ accounting for over $90 \%$ of the variance may be different.

Table 1 shows the $p_{k h}$.values for subjects 13, 14, 39, and 74 in variables $D$ and $A N$. For instance, the value .221 was obtained by multiplying the factor loading .672 , for subject 13 , by the factor loading 329 , for variable $\mathrm{D}$; and the $p_{k k}$. value of 404 , in the same table, resulted from the product of .640 , for the second factor corresponding to subject 39 , and .632 , the loading in the first factor for variable $A N$. Therelore, the agreement between subject 13 and subject 39 in terms of variable $D$ may be appraised by finding out the relationship between the corresponding $p_{k k}$, values. Similarly, by fixing the subject and changing the variables, the relationship between the corresponding $p_{k k}$. values wil] indicate how each subject relates to the variables in question.

The correlations between subjects $13,14,39$ and 74 are given in Table 2.

Table 2

Correlations between the Four $p_{k k}$. Values of Four Subjects who Obtained a Score of 1.010 in Data Gathering

\begin{tabular}{ccccc}
\hline & \multicolumn{4}{c}{ Subjects } \\
Subjects & 13 & 14 & 74 & 39 \\
\hline 13 & - & & & \\
14 & .650 & - & & \\
74 & .479 & $.981^{* *}$ & - & - \\
39 & -.060 & $.737^{*}$ & $.848^{*}$ & - \\
\hline
\end{tabular}

$* p<.05, * * p<.0$ !.

Table 2 shows the correlations between the four $p_{k k}$ values of four persons who obtained the same score in variable $D$. The association between subjects 13 and 39 is slightly negative, whereas between subjects 14 and 74 , is significant at the $1 \%$ level, in spite of the fact that all of them obtained the same score in the same variable.

Table 3

Varimax Solution for the Data shown in Table 2

\begin{tabular}{ccc}
\hline & \multicolumn{3}{c}{ Factors } \\
Subjects & 1 & 2 \\
\hline 13 & .996 & .087 \\
14 & .580 & .829 \\
74 & .400 & .916 \\
39 & -.147 & .989 \\
\hline
\end{tabular}

As shown in Table 3, the first factor for the varimax solution of these correlations is loaded in person 13, and, to a lesser degree, in persons 14 , and 74 , whereas person 39 has a negative (-147) loading in Factor 1 and a high positive loading (.989) in Factor 2.

The next problem to be explored refers to the significance of the differences between the correlation coefficients, $r$, between subjects who obtained the same score in a given variable.

Under the assumption that the sum, $T$, of the squared differences between the standard scores, $\left(z_{\mathrm{r}}-z_{\mathrm{r}}\right)^{2}=t$, is 0 for $r=1$, and a maximum for $r=-1.00$, the following approach was used to characterize the differences between correlation coefticients. For $N$ cases, the difference between standard scores is given by:

$\sum^{N}=\sum^{N}\left(z_{x}-z_{y}\right)^{2}=\sum z_{x}^{2}+\sum z_{y}^{2}-2 \sum z_{x} z_{y}=T$.

But

$\sum z_{x}^{2}=\sum z_{y}^{2}=N$

and, for $N$ observations,

$2 \sum z_{x_{y}}=2 N r$

Consequently,

$\mathrm{T}=N+N-2 N r=2 N-2 N r=2 N[1-r]$.

and $r=1-\frac{T}{2 N}$

Then, for $r=-1.00, T=4 N$.

Therefore, for values of any magnitude, $T$ will have a linear relationship with the values of $r$, from $T=0$ for $r$ $=1.00$, to $T=4 N$ for $r=-1.00$. This relationship is shown for several values of $r$ and $N$ in Figure 1 .

An analysis of variance between the sets of $t$ values corresponding to different correlations was used to find out the significance of the difference between the corresponding correlation coefficients.

For the pairs of subjects (13-14), (13-74), (13-39), (1474), (14-39), and (74-39), the correlations were $.650, .479$, $-.060, .981 .737$ and .848 , respectively. In Table 4 are shown the $t$ values and their sum, identified by $T$.

A simple analysis of variance of the $t$ values showed $F(5,18)=3.099, p<.05$. As shown in Figure 1, the relationship between the values of the correlation coefficients and the $T$ values is linear, with a maximum of 16 for a correlation of -1.00 , and .00 for a correlation of 1.00 , with a slope of 8 when $N=4$.

The varimax solution shown in Table 3 clearly separates subject 13 from the rest of subjects who obtained the same 
Table 4

Correlations $t$ Values, and their Sum (T) for Six Pairs of Subjects

\begin{tabular}{lcccccc}
\hline \multirow{2}{*}{ Correlations } & $(13-14)$ & $(13-74)$ & $(13-39)$ & $(14-74)$ & $(14-39)$ & $(39-74)$ \\
\hline$t$ values & .650 & .479 & -.060 & .981 & .737 & .848 \\
& .732 & .906 & 1.026 & .009 & .025 & .004 \\
& .017 & .070 & .687 & .018 & .487 & .318 \\
& .390 & .762 & 3.046 & .062 & 1.256 & .761 \\
& 1.819 & 2.433 & 3.724 & .045 & .338 & .137 \\
\hline$T$ & 2.958 & 4.171 & 8.503 & .134 & 2.106 & 1.220 \\
Mean & .739 & 1.043 & 2.121 & .033 & .526 & .305 \\
\hline
\end{tabular}

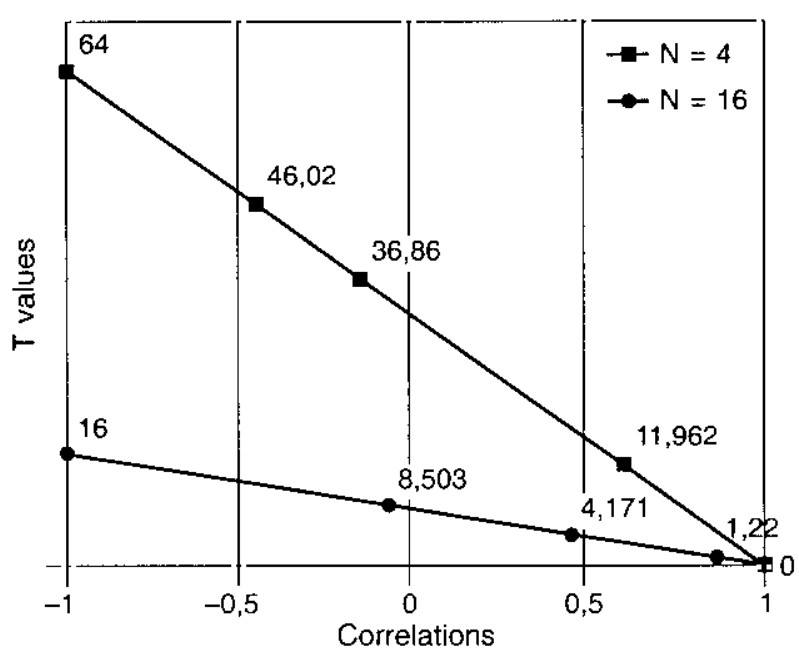

Figure 1. Relationship between correlations and $t$ Values for $N=4$ and $N=16$.

score in variable D. In other cases, for other variables and other subjects, the picture may be different. In an unpublished study, the same analysis shows a similar picture when comparing normal men, normal women, and psychotics of both sexes in personality variables, in which all of them obtained the same score. Therefore, judging from the results obtained, we suggest that the same score in a given variable requires a different interpretation, depending on the persons involved. This situation is well known by physicians and clinical psychologists, who know that the same symptom may mean different things, depending on the person or the situation that prevails at the time; therefore, to equate two persons because they obtain the same score on a test may be a risky conclusion unless the persons involved are taken into account.

The next problem to be considered is related to the fact that, regardless of the overall correlation between two variables, different subjects may show different degrees of agreement or disagreement in the way in which they relate them. For instance, although two variables may have a high positive correlation, some of the subjects in the group may disagree in the way they relate them, and, on the other hand, in spite of a low correlation between variables, some subjects may show a high relationship between these variables.
Tabie 5

$p_{k k^{\prime}}$ Values of Two Subjects in Data Gathering (D) and Anxiety Test (AN)

\begin{tabular}{cccc}
\hline \multicolumn{2}{c}{ Subject 13 } & \multicolumn{2}{c}{ Subject 39 } \\
$\mathrm{D}$ & AN & $\mathrm{D}$ & AN \\
\hline .221 & .425 & .115 & .220 \\
.100 & .191 & .211 & .404 \\
.440 & .241 & .229 & .125 \\
.198 & .109 & .420 & .230 \\
\hline
\end{tabular}

To investigate this problem, we computed the correlations between the $p_{k k}$, values for different subjects in several variables. In a way, this is the opposite of the previous procedure, in which a fixed variable was examined with different subjects. Now a fixed subject is examined with different variables. For instance, for subjects 13 and 39 (see Table 1) the relationship between variables $D$ and $A N$ in each one is obtained by correlating the values shown in Table 5. The same is true for other subjects in other variables.

Table 6 shows the correlations between the variables R/PM, R/AN, R/SE, PM/AN, PM/SE, and AN/SE for subjects $19,123,39,54,13,30$, and 71 . This implies finding, for each subject, the $p_{k k}$, values for each variable. Note that, whereas all subjects agree in the relationship between variables $\mathrm{R} / \mathrm{PM}, \mathrm{R} / \mathrm{SE}$, and $\mathrm{PM} / \mathrm{SE}$, subject 123 departs radically from the rest (except for subject 19) in terms of the association between variables R/AN, PM/AN, and AN/SE, which are highly negative.

In Figure 2, the values from Table 6 are presented graphically. As can be observed, in terms of variables, there are two groups, one corresponding to variables $R / P M, R / S E$, and PM/SE and the other to the remaining pairs of variables. Similar findings have been observed in other sets of data that we are now examining. This helps to understand how subjects differ - or agree - on the way in which they perceive the relationship between variables. In short, as shown in Figure 2, there is a high degree of agreement among all the subjects in the way in which they associate the variables R/PM, R/SE, and PM/SE. However the way in which variables PM/AN, R/AN, and AN/SE are related 
Table 6

Correlations between the $p_{k k}$. Values of Pairs of Variables, for Seven Subjects

\begin{tabular}{|c|c|c|c|c|c|c|c|}
\hline \multirow[b]{2}{*}{ Variables } & \multicolumn{7}{|c|}{ Subjects } \\
\hline & 19 & 123 & 39 & 54 & 13 & 30 & 71 \\
\hline $\mathrm{R} / \mathrm{PM}$ & 1.00 & 1.00 & .999 & .999 & .999 & .999 & .999 \\
\hline $\mathrm{R} / \mathrm{AN}$ & -.993 & -.981 & .144 & .272 & .355 & .533 & .542 \\
\hline $\mathrm{R} / \mathrm{SE}$ & 1.00 & .999 & .956 & .956 & .957 & .962 & .963 \\
\hline $\mathrm{PM} / \mathrm{AN}$ & -.992 & -.979 & .187 & .311 & .392 & .562 & .571 \\
\hline PM/SE & .999 & .998 & .942 & .943 & .945 & .952 & .953 \\
\hline AN/SE & -.996 & -.998 & -.153 & -.022 & .070 & .283 & .295 \\
\hline
\end{tabular}

Note $. \mathrm{R}=$ Reading Test $; \mathrm{PM}=$ Patient Management $\mathrm{AN}=$ Anxiety Test $; \mathrm{SE}=$ Self-Esteem

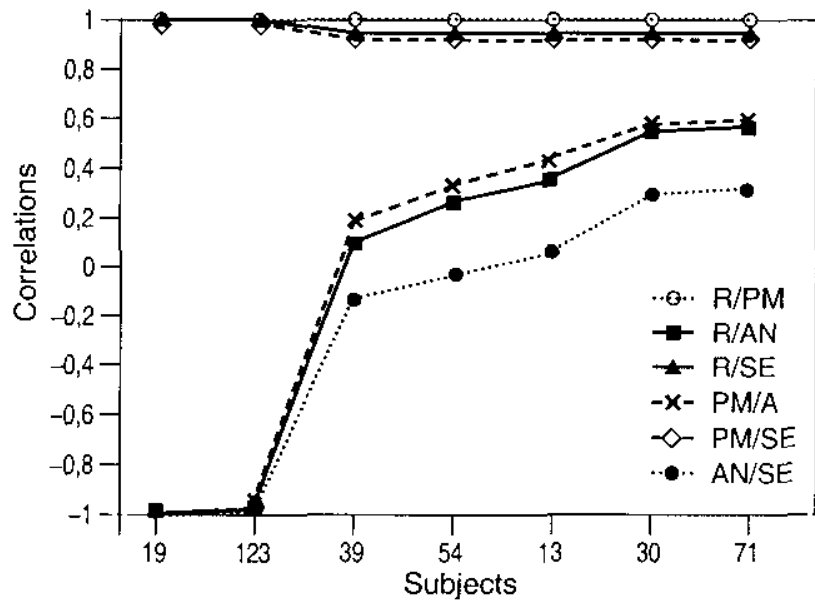

Figure 2. Correlations of seven subjects between variables R/PM, R/AN, R/SE, PM/AN, PM/SE, and AN/SE. R = Reading Test; $\mathrm{PM}=$ Patient Management; $\mathrm{AN}=$ Anxiety Test; $\mathrm{SE}=$ Self-Esteem.

varies with the subject. Thus, subjects 71 and 30 are clearly differentiated from subjects 19 and 123 in the way in which they relate variables $\mathrm{PM} / \mathrm{AN}$ and $\mathrm{R} / \mathrm{AN}$. With reference to the association between variables $\mathrm{AN} / \mathrm{SE}$, they are equally associated in subjects 30 and 71 and negatively related in the case of subjects 19 and 123 .

This information may be used to select the variables that will provide a better overview of the subjects involved, taking into account how they relate variables. For instance, none of the subjects reported here showed differences in the way they related variables $R / P M, R / A N$, and PM/AN, so it would be unnecessary to consider all of them. On the other hand the association between variables PM/AN, R/AN, and $\mathrm{AN} / \mathrm{SE}$, helps to differentiate them.

In Table 7, we present the correlations between $p_{k k}$ ' values of pairs of subjects, taking into account their scores in variables $R, P M, A N$, and SE. The product of the two $p_{i k}$. values for each subject with the two $p_{j k}$ values for each variable, gave a tolal of $16 p_{k k}$. values for each of the seven subjects. Note that the range of these correlations, as shown in Table 7, varies considerably. For instance, subject 13 shows a correlation of 999 with subject 54 , but of only -.438 with subject 71 . In Table 8 , the results of a varimax solution are shown. In terms of the factor loadings, the seven subjects can be classified into two groups: one defined by subjects 30, 39, and 71, who have high loadings in Factor 2 and loading near zero in Factor 1, whercas the remaining four subjects are mainly loaded in Factor 1 .

The analyses of variance indicated that the correlation between subjects 13 and 19, with a value of .626 (see Table 7), and the correlation of -.152 between subjects 54 and 39 were significantly different at the $1 \%$ level, $\quad F(1,30)=17.656$, whereas the comelations of -.438 and -.152 , between subjects 13 and 71 and subjects 54 and 39 , respectively, were not, $F(1$, $305=1.279$.

Table 7

Correlations between the $p_{k k}$. Values of Pairs of Subjects Taking into Account Variables $R, P M, A N$, and SE

\begin{tabular}{|c|c|c|c|c|c|c|c|}
\hline \multirow[b]{2}{*}{ Subjects } & \multicolumn{7}{|c|}{ Subjects } \\
\hline & 19 & 123 & 39 & 54 & 13 & 30 & 71 \\
\hline \multicolumn{8}{|l|}{19} \\
\hline 123 & .999 & & & & & & \\
\hline 39 & .637 & .612 & & & & & \\
\hline 54 & .665 & .689 & -.152 & & & & \\
\hline 13 & .626 & .651 & -.202 & .999 & & & \\
\hline 30 & .433 & .403 & .971 & -.386 & -.432 & & \\
\hline 71 & .426 & .397 & .969 & -.392 & -.438 & 1.00 & \\
\hline
\end{tabular}

Note $\mathrm{R}=$ Reading Test; $\mathrm{PM}=$ Patient Management $\mathrm{AN}=$ Anxiety Test $; \mathrm{SE}=$ Self-Esteem. 
Table 8

Varimax Solution for the Data shown in Table 7

\begin{tabular}{lrr}
\hline & \multicolumn{2}{c}{ Factors } \\
Subjects & 1 & 2 \\
\hline 13 & .937 & -.349 \\
54 & .953 & -.302 \\
30 & -.089 & .996 \\
123 & .875 & .483 \\
19 & .859 & .512 \\
39 & .153 & .988 \\
71 & -.097 & .995 \\
\hline
\end{tabular}

\section{Final Comments}

The overall conclusion indicates that the joint proportional contribution to a given score of factors due to variables and factors due to persons is an important element to be considered when evaluating individual differences. In other words, the uniqueness of each person, expressed quantitatively, is an important element to consider in any judgement based on the examination of obtained scores, given that two or more persons may reach the same result in entirely different ways.

\section{References}

Burger, G.K., \& Rimoldi, H.J.A. (1997) Using person factors to determine variable factors: An application with the MMPl. Interdisciplinaria, 14, 81-91.

Burt, C. (1937). Correlation between persons. British Journal of Psychology, 28, 59-95.

Burt, C. (1941). The factor of the mind: An introduction to factor analysis in prychology. New York: Macmillan.

Cattell, R.B. (1950). Personality. A systematic theoretical and factorial study. New York: MacGraw Hill.

Cattell, R.B. (1952). The three basic factor-analytic research designs: Their interrelations and derivatives. Psychological Bulletin, 49. 499-520.

Cattell. R.B. (1963). The structuring of change by P-technique and incremental R-technique. In C.W. Harris (Ed.), Problens in measuring change (pp.167-198). Madison, WI: University of Wisconsin Press.

Cattell, R.B. (1965). The scientific analysis of personality. Harmandsworth, UK: Penguin.

Cattell, R.B. (1978). The scienific wse of fuctor analysis. New York: Plenum Press.

Cattell, R.B. (1979). Personality and learning theory. I. The struchure of personality in its environment. New York: Springer.

Cattell, R.B. (1980). Personality and leaming theory. 2. A systens theory of maturation and structured leorning. New York: Springer-Verlag.
Cronbach, L. J. (1992). Some choices in factor analysis. In Facultad de Psicología (Ed.), Inteligencia y cognición, homenaje al Prof. Mariano Yela Granizo (pp. 465-474). Madrid: Editorial Complutense.

Hakstian, A.R., \& Cattell, R.B. (1978). An examination of interdomain relationships among some ability and personality traits. Educational and Psychological Measurement. 38, 275 . 290.

Hojat, M., Erdmann, E., Robeson, M., Damjanov, Y., \& Glaser, K. (1992) A study of psychometric characteristics of abridged versions of selected psychological measures given to medical school students for the purpose of predicting their clinical competence. Interdisciplinaria, $/ 1,129-148$.

Holley, J.W. (1964). A note on the relationship between $Q$ and $R$ factors. Scandinavian Joumal of Psychology, 5, 143-148.

Holley, J.W. (1970). On the generalization of the Burt reciprocity principle. Multivariate Behavioral Research, 5, 241-250.

Holley, J.W., \& Guilford, J.P. (1964). A note on the G index of agreement. Educational and Psychological Measurement, 24, 749-753.

Holley, J.W., \& Harris, C.W. (1970). The application of the Harris Bridge in the generalization of the Burt reciprocity principle: A demonstration study. Scandinavian Journal of Psychology, 2, 255-260.

Horst, P. (1963). Matrix algebra for social scientists. New York: Holt, Rinehart, \& Winston.

Levin, J, (1964). Three mode factor analysis. Dissentation Abstracts, 24, 5530-5531.

Rimoldi, H.J.A. (1990). Finding relations between systems of entities: A multivariate approach. Archiv fir Psychologie, 142 , $211-223$.

Sandler, J. (1949). The reciprocity as an aid to factor analysis. British Journal of Psychology: Statistical Section, 2, 180-197.

Sandler, J. (1952). A technique for tacilitating the rotation of factor axes, based on an equivalence between persons and tests. Psychometrika, 17, 223-229.

Stephenson, W. (1935). Correlating persons instead of tests. Character and Personality, 6, 17-24.

Stephenson, W. (1936). The inverted factor analysis. British Joumal of Psychology, 26, 344-361.

Stephenson, W. (1953). The study of behavior: Q-technique and its methodology. Chicago, IL: University of Chicago Press.

Thomson, G.H. (1951). The factorial analysis of human ability. London: University of London Press.

Thurstone, L.L. (1969). Multiple-factor analysis. A development and expansion of the vectors of mind. Chicago, $\mathrm{HL}_{\text {. }}$ University of Chicago Press.

Tucker, L.R. (1967). Implications of factor analysis of three way matrices for measurement of change. In C. W. Harris (Ed.), Problens in measuring change (pp. 122-137). Madison, WI: University of Wisconsin Press.

Received August 29, 1997

Revision received February 2, 1999

Accepted May 24, 1999 